Yaratıc1 Drama Dergisi

2007, Cilt 1, Say1 3-4

\title{
Oyuncu Eğitimi İçin Farklı Doğaçlama Yöntemleri
}

\author{
Selda ERGÜN.
}

Dokuz Eylül Üniversitesi

\section{Özet}

Bu çalışma tiyatro oyunculuğunda doğaçlama yöntemini tanıtarak, tiyatro oyuncusunun eğitiminde doğaçlamaya dayalı farklı yöntem üreten sanatçıların yöntemlerine yer vererek, oyuncuya ve oyunculuk eğitimine yararlı olacak, yol gösterecek temel mesleki kaynaklarl ortaya koyarak, oyunculuk eğitimini zenginleştirmeyi hedeflemektedir. Oyunculuk eğitimi için ilk sistemli çallşma yöntemi ortaya koyan sanatçı Stanislavski nin yönteminden başlayarak günümüze kadar zengin bir kaynak sunan sanatçıların çağdaş tiyatronun oyunculuk eğitimi için doğaçlama yöntemini merkeze alarak ürettikleri yöntemleri tanıtılacaktır. Çalı̧̧manın son bölümünde ise tanttılan bu yöntemlerin, var olan oyuncu eğitimine alternatif oluşturarak, oyuncunun hazırlanmasına nasıl katkıda bulunabileceği açımlanacaktır. Bu çalışma, oyunculuk eğitimi veren kurumlara, tiyatro topluluklarına ve yaratıcı drama çalışmalarına öneriler üretmek ve yeni yöntemlerle tanıştırarak, yaratıcılığın önünü açmayı amaçlayan bir inceleme olarak değerlendirilmelidir.

Anahtar sözcükler: Doğaçlama, oyuncu, temrin

\begin{abstract}
This study is aimed at introducing improvisation methods and enriching acting education by exhibiting pilot fundamental vocational sources through sloting artists methods who creates new methods about improvisation for theater actors that be useful for actor and acting education. Acting education methods of artists who have presented productive sources will be investigated in the base of starting with the methods of Stanislavski who put forth the first systematic studying method for acting education and improvisation methods till to today's improvisation methods. In the last part of the study, it will be explained that how these methods contribute for actor's preparation by being alternative for substantial actor education. This study must be evaluated as a survey that aiming at creating a proposal for acting education institutions, theater companies and creative drama workings and opening out initiative of creativity by introducing new methods.
\end{abstract}

Keywords: Improvisation, actor, training

\footnotetext{
·Yrd. Doç. Dr., Dokuz Eylül Üniversitesi, Güzel Sanatlar Fakültesi, Sahne Sanatları Bölümü, Oyunculuk Ana Sanat Dall, E-posta: selda.ergun@deu.edu.tr
} 


\section{Giriş}

Tiyatro oyunculuğu eğitimi alanında sistemli yöntemlerin gelişimi 20.yüzyılla birlikte hız kazanmıştır. $\mathrm{Bu}$ dönemde yaşanan savaşlar, bilimsel ve teknolojik gelişimler dünyayı derinden etkilemiş ve birçok alanda olduğu gibi, tiyatro oyuncusunun eğitimine yaklaşımda farklılıklara neden olmuştur. Dönem koşulları karşısında düşünürlerin görüşlerinin ortak noktası, teknolojik gelişimlerin tehlikesi ve insanda yarattığı olumsuzluklar üzerinedir. Toplumsal sorunların yansımaları; insanlar arasında güvensizlik, tehlike içinde olmak, inançsızlık, umutsuzluk ve bunların sonucunda tepkisizlik, eylemsizlik ve aynılaşma gibi olumsuzlukları içerir. Bu sorunlarla baş etmek için önerilen yöntemler içinde Herbert Marcuse' nin insanın değişmesi gerektiği düşüncesi öne çıkar;

“Önemli olan kurumları değiştirmek değildir. Önemli olan insanı değiştirmek, görüşlerine yeni bir yön vermek, içgüdülerini yeniden biçimlendirmek, hedeflerini tazelemek ve değer ölçülerini yeni baştan düzenlemektir." (Hançerlioğlu, 1995: s.458).

Görüşlerin temelinde insanın koşulların kurbanı olması yerine, durumunun farkına varması ve bireysel gelişimi ile toplumsal değişime ön ayak olması düşüncesi yatmaktadır. Yaşamın her alanında benimsenmeye başlanan bu görüşler tiyatro sanatçıları tarafından da benimsenir:

“Tiyatro, yabancılaşmış, mutsuz ve güşüz düşmüş insana çıklş yolu göstermeli, onun eski sağlığına, iç uyumuna ve toplumsal dengesine kavuşmasına yardım etmelidir." (Şener, 1991: s.365)

Gelişen yaşam koşullarının sığlaştırdığı insanı yeniden yaratmak, insanı önceden olduğu gibi naif, masum, kendi ve çevresi ile barışık, maskeye gereksinim duymadan doğal davranabilir hale getirmek tiyatro sanatçılarının hedefi olur.

Tiyatronun insanın özüne inme ve kendini bulma aracı olduğu düşüncesinden hareketle, oyunculuk da bir yaşam eğitimine dönüşür. Oyuncuyu temel alan bu çalışmalarda, oyuncuda insanı araştırmak amaçlanmaktadır. Böylece oyuncu aldığı eğitim ile kendi hakkında bilgi edinip, kendini değiştirirken, tiyatro yaşantısını bütünleyen ve bu yaşantıyı paylaşan seyircisinin de değişmesine olanak hazırlayacaktır. Yaşadıkları dönemin tiyatro anlayışına karşı, yeni arayışlar içinde olan tiyatro sanatçılarının bir araya gelerek oluşturdukları küçük gruplarla gerçekleştirdikleri disiplinli ve deneysel çalışmaları ile tiyatro oyuncuları için yeni yöntemler oluşmaya başlamıştır.

Çalışmalarda temel hedef, zihinsel ve bedensel gelişimi sağlamaktır. Geliştirdikleri farklı yöntemlerle oyunculuğu zenginleştirmeye çalışan çağdaş tiyatro sanatçılarının ortak amaçları söyle sıralanabilir: Oyuncunun kendini tanıması ve böylece kendini dışa açabilmesi, kendini ve çevresini daha iyi gözlemleyebilmesi, kendi ile diğerleri arasındaki benzerlik ve farklılıkların ayırdına varabilmesi, çevresindeki insanlar ve nesnelerle ilişkilerini geliştirmesi, bunların sonucunda yaratıcılığını 
arttırabilmesi. Bu amaçla tiyatro sanatçılarının oyuncu eğitiminde doğaçlama yöntemini yoğun olarak kullandıkları görülür.

\section{Doğaçlama Kavramı}

Kullanım amacına göre farklı tanımlara sahip olan doğaçlamayı, oyuncu eğitiminde öncelikle oyuncunun kendi olanaklarını tanıması, keşfetmesi, sınırları ile yüzleşmesi ve sınırlarını genişletmesini sağlamak için kullanılan bir yöntem olarak tanımlayabiliriz.

Gözlem bu çalışmalarda önemli bir yere sahiptir. Algıları geliştirme, imgelemi zenginleştirme, karşılıklı etkileşim ve ritim üzerine yapılan çalışmalar kişinin kendini çok yönlü tanımasına yardımcı olur. Tüm bu çalışmalar oyuncunun, monotonluktan, sıradanlıktan kurtulup, aniden gelişen olaylar karşısında yaratıcı olmasını, özellikle zihnini, bedenini ve sesini tanımasını ve tüm kapasitesiyle kullanabilmesini sağlar (Ergün, 1993: s.13).

Doğaçlamalarla erişkinlere, yeniden oynayabilme, oyun oynamanın yaşamdaki birçok duygunun ifadesine olanak tanıdığını hissettirebilme, yaratabilme, yaratıcı olabilme becerisi kazandırma, toplumun öngördüğü, belirlenmiş, donuk bir yaşamı tekdüze sürdürmek yerine, yeni alternatiflerle yaşamını renklendirme, çeşitlendirme, zenginleştirme olasılığı sunma... gibi zengin ve bir o kadar da iddia taşıyan hedefler üzerine gidilmektedir. Hayal gücünün çalıştırılması, doğaçlamalarda orada o anda üretilmesi yaşam zenginliği kazandırır. Doğaçlama oyun ile değişik roller sınanabilir. Kişi dilediği tüm rolleri oynayabilir. Böylece kendini tanımada önemli bir adım atmış olur.

Kendini tanıma, yaşamını istediği gibi yönlendirme ve kendi sorumluluğunu tek başına taşıma yeteneklerinin gelişmesi bireyin yaşamını daha anlamlı kılar. Kendini tanıyan kimse, dikkatini içinde bulunduğu duruma ve çevresindeki diğer insanlara kolayca, serbestçe ve ön yargılara kapılmadan verebilir, esneklik kazanır ve yaşam karşısında daha cesur olmaya yönelebilir.

Doğaçlamalarda bireysel gelişim yanında grup dinamiğini oluşturma ve güçlendirme gibi amaçlar da iç içe ilerler. Doğaçlamalar kendini tanıyan kişinin çevresindeki dünya ile kurduğu dolaysız, kendiliğinden ilişkileri güçlendirir. Gerçekleştirilen doğaçlamalarla, kişinin tamamen kendi dışında farklı sosyal konumlarla karşılaşmasına olanak sağlamak ve böylece kişinin kendine daha güvenli olmasını ve diğer insanlarla ilişkilerinde deneyim kazanmasını sağlamak gibi amaçlar gözetilir. 


\section{Doğaçlamanın Çıkışı}

Doğaçlamanın ilk ne zaman ortaya çıktığını, kullanılmaya başlandığını saptamak zordur. Taklidin olduğu her yerde doğaçlama vardır. İnsanlık tarihine baktığımızda ilkel toplumların içgüdüsel ve basit anlatımlarla oyun, dans, hareket, mimik, pandomim, söz, şarkı ve müzikle av, bereket, çoğalma gibi yansılamalarda doğaçlamaya yer verdiği söylenebilir.

Doğaçlama tiyatrosunun ilk örneklerine ise antik çağda Mimus ve Pantomimus'ta rastlanmaktadır. Mimus basit olayların taklidi, avcı, köle, aşçı, tayfa, çiftçi, balıkçı, çoban, asker, sokak kadını, dilenci, fırıncı, ayakkabıcı, dadı gibi halkın temsilcilerinin eleştirel, burlesk yansıtılmasıydı. Bu sanatçılar halktan gelip halk için oynuyorlard. Mimuslar tamamen doğaçlamaydı ve kaba ama gerçekçi taklitlerle halkı eğlendiriyorlardı (Ebert, 1999: s.18). Zaman içinde Mimusların yerini doğaçlama ile yazılan oyunlar almaya başlamıştır. 15. yüzyıl sonu, 16. yüzyıl başında İtalya' da gelişen, İtalyan halk doğaçlama tiyatrosu olan Commedia dell' Arte ile oyuncu odaklı tiyatroya tekrar dönüş yaşanmıştır. Bu tür, geleneksel Yunan ve Roma farslarından alınan unsurlarla geliştirilmiştir. Commedia dell' Arte' de bir taslak senaryoya/kanavaya dayanılarak, bütün oyuncular canlandırdıkları tiplerin özelliklerini yorumlamak için bir ön hazırlığa girişir. Oyuncular belirli maskeler kullanarak, belirli tipleri canlandırırlar ve belli duruma, yere, zamana ve izleyiciye göre olayı pandomim, akrobatik numaralar gibi ustalığa dayalı beceriler de kullanarak doğaçlamalarla oynarlar. Bu tür bir oynama biçemi üç yüz yıldır tiyatroyu etkilemektedir. Asya Tiyatrosu'nda ve Geleneksel Türk Tiyatrosu'nda doğaçlama yöntemi yaygın olarak kullanılmaktadır.

Ancak, daha çok halk tiyatrolarında görülen bu oyunculuk ve sahneleme anlayışının yanı sıra, özellikle 19.yy.'ın ikinci yarısından başlayarak yazar egemenliğinde ve doğaçlamaya dışlayan bir tiyatro anlayışı uzun süre tiyatroda egemen olmuştur. 1960'lardan itibaren çağdaş tiyatro sanatçılarının oyuncu odaklı tiyatro anlayışları yeniden yaygınlık kazanmaya başlamıştır.

1960' ların zengin sanat ortamında birbiri ardına oluşturulan oyuncu çalışma laboratuvarları ile oyunculuk yöntemleri çeşitlilik kazanarak, doğaçlamaya dayalı oyunculuk eğitim yöntemleri günümüz oyunculuğuna temel oluşturmaya başlamıştır. Bu dönemde doğaçlama yöntemi ile çalışan sanatçılardan bazıları doğaçlamayı tiyatroda karakter yaratmada bir yöntem olarak ele alırken bazıları ise oyuncunun kişisel gelişimi için doğaçlamayı vazgeçilmez bir yöntem olarak ele almıştır.

Doğaçlama yöntemi oyuncu eğitiminin yanı sıra, oyun sahneleme, oyun yazma gibi farklı amaçlarla da kullanılmaktadır. 


\section{Farklı Doğaçlama Yöntemleri Geliş̧iren Sanatçılar}

Tiyatro tarihininde, sistemli çalışma yöntemini geliştiren ve oyuncu eğitimi için doğaçlama yöntemi üreterek günümüze kadar belirleyiciliğini sürdüren belli başlı tiyatro sanatçıları arasında; Kontanstin Stanislavski, Vsevolod Emilyeviç Meyerhold, Bertolt Brecht, Lee Strasberg, Mikhael Chekhov, Eric Morris, Jerzy Grotowski, Thomas Richards, Eugenio Barba, Peter Brook, Viola Spolin, Joseph Chaikin, Augusto Boal ve Keith Johnstone sayılabilir.

Kontanstin Stanislavski: 20. yüzyılda yöntemini geliştiren Stanislavski, doğaçlamanın modern kullanımının öncüsü sayılabilir. 1930'larda geliştirdiği gerçekçi oyunculuk yöntemiyle 'oyuncunun zihinsel, fiziksel, ruhsal, coşkusal tüm yetilerini' geliştirerek seyirciye sunabilecek hale gelmesinin yolunu açmıştır. 'Gözlem', 'büyülü eğer', 'duygu belleği', 'üstün amaç' ve 'konsantrasyon' gibi temrinler üreterek sistemli bir çalışma yöntemi sunmuştur. Stanislavski'ye göre oyuncu:

“(...) Kendi insanlık niteliklerini rol kişisinin yaşaylşına uydurmalı, ruhunu bütünü ile o kişinin içine boşaltmalıdır"(Stanislavski, 1993: s.27).

Stanislavski doğaçlamayı karakter yaratmada bir yöntem olarak kullanmıştır. İçten dışa doğru diye tanımlanan bu yöntemde, yaratıcılığın ortaya çıkarılması hedeflenir; oyuncu duygularını ortaya çıkararak, rolünü oluşturur:

"Stanislavski oyunculuk dizgesinde, oyuncunun geçmişteki deneyimlerini, hazırladı̆̆ rolü doğru bir biçimde ortaya çıkarmasında duygu belleğine başvurur. Oyuncunun bir melodiyi, bir sesi, bir yüzü, acı bir olayı ya da mutlu bir anı anımsayarak rolündeki hareketleri ve konuşmayı saptaması duygu belleği ile olur(...)” (Nutku, 1998: s.61).

Stanislavski, son yıllarında, karakter çözümlemesinde psikolojik ve sosyolojik etmenlerin yanı sıra çevre, içinde bulunulan mekan etmenini de ekleyerek daha derinlikli bir yaklaşım yöntemi getirmiştir.

Stanislavski oyunculuk sanatına yeni bir yöntem getirmiş ancak uzun bir döneme yayılan araştırma ve denemelerinin tümünü bir araya toplayıp, yayımlayamadan yaşamını kaybetmiştir. Sanatçı öleceği güne kadar araştırma ve denemelerini sürdürmüştür ve bu nedenle yaptığı çalışmaların değişmez katı kurallar olarak benimsenmesinden hep kaygı duymuştur. Yönteminin başka sanatçılara 1şık tutacağı ve yeni atılımlara hız kazandıracağı düşüncesini benimsemiştir.

Vsevolod Emilyeviç Meyerhold: Stanislavski' nin ardından, onun uygulama sahnesinin başına geçen Meyerhold, Stanislavski oyunculuk anlayışına ve Gerçekçi Tiyatro'ya karşı çıkarak, oyuncunun anlatım olanakları üzerinde durmuştur. Yöntemi dıştan-içe oyunculuk diye tanımlanabilir. Duygu durumları, seyirciye gösterilmesi gereken anlatı, hareketten yola çıkarak oyuncuyu bir iç yolculuğa sürükler. Bu iç yolculuk sayesinde sahne ve mizansen anlam kazanır [1]. 
Geliştirdiği ‘biyomekanik' tekniği ile oyuncunun üç boyutlu, hareketli ve mekan içinde devinen bir yontu olduğundan hareketle, oyuncunun çalışmasında tiyatro ritmiyle ve sahneye özgü kurallarla bir biçem geliştirmek üzerinde yoğunlaşmıştır.

Biyomekanik, belli kas etkinlikleri ile istenilen duyguların refleks olarak üretilmesidir. Stanislavski' nin aksine iç eylem yerine, fiziksel eylemler ve onların sonucunda kazanılan duygusal iç tepkileri vurgulamıştır. Meyerhold' a göre "beden bir makine, oyuncu da bir makinisttir" (Picon-Vallin, 1997: s.322).

Biyomekanik yöntem ile Ekim Devrimi' nde benimsenen açılım tiyatroya da yansır; oyuncunun işçinin çalışma düzenine benzer bir yaklaşım içinde olması, gerçekci oyunculukta rastlanan "fazla" hareketlerden arınması yani anlatımda ekonomiklik savunulur. $\mathrm{Bu}$ anlayışa göre, sanat, bilimsel temellere oturmalı, oyuncunun devinimleri bilinçli bir süreç oluşturmalıdır [2].

Bertolt Brecht: 20. yüzyıl tiyatrosunda en köklü değişimleri gerçekleştiren Brecht, oyunculuk için 'toplumsal jest' ve 'yabancılaştırma' tekniklerini geliştirmiştir. Meyerhold' un çalışmalarından da etkilenen sanatçı, 'Epik Tiyatro' akımının temsilcisidir. Amacı sahnede toplumsal gerçeği, somut ve yaşayan tablolarla göstererek, seyirciyi düşündürmek ve sorgulamaya yöneltmektir. Bunun için sahne ile seyirci, sahne ile oyuncu ve oyuncu ile rolü arasında bir uzaklık yaratabilmek için yabancılaştırma yöntemini kullanır. Bu teknikte oyuncu canlandırdığı kişiyi olmak ya da betimlemek yerine gösterir. Oyunculukta gestus (toplumsal tavir) ile ifade edilen bu teknikle oyuncu, toplumsal anlamı ifade eden tavırla oynar, seyredildiğinin bilincindedir ve kendini de seyredebilmelidir (Brecht, 1981: s.123).

$\mathrm{Bu}$ yöntemle çalışan oyuncu, Stanislavski yönteminden farklı olarak çalıştığı karakter ile özdeşlik kurmaz, oynadığı kişiye dönüşmez, bunun yerine oynadığı kişinin konuşma ve davranış biçimlerini ortaya koyar. Hareketleri ile toplumsal özü ortaya çıkarmayı hedefler. Bu yöntem tüm duyguları jeste dönüştürme yöntemidir.

Lee Strasberg: Stanislavski’nin öğrencisi olan Strasberg, aynı yöntemi Method Acting adı altında Amerika' da yaşama geçirmiştir. Daha sonra adı Aktörler Stüdyosu olan bu toplulukla Stanislavski’ nin 'fiziksel hareketler', 'içten dışa doğru' ve 'duygu belleği' adı altında geliştirdiği temrinlerini ele alarak farklı yorumlarla zenginleştirmiştir.

Strasberg doğal kavramının açıklanmasında Stanislavski’ den ayrılmaktadır. Ona göre verili durumlar içerisinde ‘büyülü eğerler' yoluyla rol ile yakınlıkları keşfetmek için doğaçlamalar yapmak yerine, role ait özgün duygunun oyuncu tarafından da aynı özgünlükle yakalanması adına terapi çalışmaları üzerinde yoğunlaşmak gerekmektedir (Mimesis 6, 1997: s.357). Bu yöntem ile çalışan oyuncu hiçbir zaman başka 
bir karakteri aynen oynama işine girişmez, bunun yerine canlandırdığı karakteri kendi kişiliği ile bütünleştirebilme yolunu izler.

Mikhael Chekhov: Stanislavski' nin "en iyi öğrencim” diye söz ettiği Chekhov 20.yüzyılın en önemli oyuncuları arasında yerini alır. 'Moskova Oyuncular Tiyatrosu'nda geliştirdiği yönteminde, Stanislavski’nin yöntemi ile Rudolph Steiner'ın estetik düşüncelerinden yararlanmıştır.

Temel olarak oyuncunun yaratıc1lık düzeyine nasıl ulaşabileceği ve imgelem zenginliği üzerinde durur. Yaratıcılığın raslantısal mı yoksa eğitimle mi olduğunu araştırmıştır. Chekhov' a göre oyuncu eğitiminde, kendini tanıma ve sınırlarının farkına varma doğaçlama temrinlerini, konsantrasyonu arttırma gibi temrinler izlemelidir. Ancak bu eğitim aşamaları tamamlandıktan sonra oyuncu daha bilinçli hale gelebilir ve iç resimleri görmeyi ve de onları aktarmayı başarabilir. Böylece oyuncu canlandırdığı karakteri gözünde canlandırma ve bir süre sonra da bu karakterin yaşamını hayalinde canlandırarak, onunla konuşmayı başarır hale gelebilir. Yani oyuncu, karakterin eylemlerini nasıl gerçekleştirdiğini anlayarak, içsel algı ile dış ifadeyi gerçekleştirir. Bu düzeye ulaşmak için eğitimin fiziksel ve zihinsel uyumu sağlamaya yönelik, düşünce, hissetme ve isteme arasındaki dengeyi sağlayıc1 doğaçlama temrinleri ile desteklenmesini önerir [3].

Chekhov sistemi ile doğaçlamalarda rolü zihinsel ve duygusal olarak var edip, daha sonra bunu kendine mal etmenin yöntemlerinin öğrenilmesi amaçlanmaktadır.

Eric Morris: Stanislavski yönteminden yola çıkarak yöntemini geliştirmeye başlayan bir sanatçıdır. Ancak Stanislavski metodunu uygularken bu yöntemin herkeste başarıya ulaşmadığını gözlemlemiştir.

Stanislavski sisteminde oyuncunun kendisi ile ilgili hazırlığın gerekliliğinin farkında olmamasını eleştiren Morris, yöntemini geliştirirken öncelikle 'kendi olmanın ne olduğunun aranmasıyla' başlamaya karar vermiştir. Ona göre kendini tanıyan oyuncu kendini sahnede var edebilir. 'Enstrümental çalışma' adı ile özetlenebilecek bu yöntemde Morris, Method Acting yöntemi temelli çalışmalarla, oyuncunun kendini tanıması ve ifade yollarının geliştirilmesi üzerine doğaçlamalar yapmıştır. 'Olmak', 'bilinçaltı', 'duygu belleği', 'imge', 'dış etkenler', 'yaratıcılık', 'bedensel hazırlık' gibi doğaçlama temrinleri üreterek oyuncu hazırlığına katkıda bulunmuştur (Morris ve Hotckis, 2000: s.111).

Morris bir oyuncunun ne kadar çok şeyi fark ederse o kadar çok etkileneceğini, ne kadar çok etkilenirse o kadar çeşit duygusal yaşantının olacağını ve çeşitli insanların davranışlarını yaratmada seçenek sağlayan daha fazla yaşam düzeyinin olacağını belirtir. Bu ve içsel farkındalık bir araya geldiğinde oyuncu kendi iç dünyasını tanımaya başlar ve bilinçaltının derinliklerindeki karanlık aydınlanır. Böylelikle oyuncu malzemesini en ince detaylarına dek öğrenmeye, onu eğitmeye başlar. 
Farkındalık ve bu kavramın içeriğindeki diğer önemli kavramların gelişimini kontrol edilebilir bir nitelik kazanır (Morris, 2002: s.65-80).

Morris son çalışması olan 'Fütursuz Oyunculuk' ta, tamamıyla işçilik sürecine yönelir. İnsan enstrümanına yoğunlaşarak, oyuncunun kişisel gerçeğinin önünü kesen sorunlarla ilgili doğaçlama temrinleri üretir. Özelikle de oyuncunun ne yapacağını bilirken nasıl bilmez konumda kalıp, sürprizi yaşatıp, yeşerteceği üzerinde çalışmaktadır (Morris, 2002: s.23).

Jerzy Grotowski: Stanislavski yöntemi üzerine bir eğitim alan ve Stanislavski'den sonra laboratuvar çalışmasını en sistemli biçimde yürüten Grotowski, kendi oyunculuk anlayışını ortaya koyarak, Batı Tiyatrosu' nun oyunculuk anlayışına yeni bir bakış açısı getirmesi, oyuncunun ses ve beden denetimini ve çalışma disiplinini ön plana çıkarması ile belirleyici olur. Grotowski, oyuncu eğitiminin insanın kendisi ile ilgili gerçeği bulması ve her gün ardına gizlendiği maskelerden kurtulmayı denemesi için gerekli olduğuna inanır (Mimesis, 1997: s.2).

Avrupa ve Avrupa dışında önemli tüm oyuncu yetiştirme yöntemlerini araştıran Grotowski’ nin yöntemi, sürekli denemeler yaparak ilerlemek olmuştur. Grotowski, bir oyuncu sanatı olarak tiyatronun Stanislavski' de doruğa ulaştığına inanır. Ancak uzun soluklu çalışmaları sonucu Stanislavski yönteminde bazı eksiklikler saptar; anlık iletişimin göz ardı edilmesinin büyük hata olduğu görüşündedir. Ona göre oyuncu için 'şimdi' ve 'burada' olmak önemlidir.

Grotowski, oyunculuğun Stanislavski' den farklı olarak 'esinlenme' ya da 'yetenek patlamaları' gibi yaratıcı olanakların ansızın ve şaşırtıcı bir biçimde artması gibi önceden kestirilemeyen yaratıcı niteliklere dayandırılamayacağını savunur. Yaratıcılık ancak yöntem öğrenilerek oluşturulabilir (Çalışlar, 1993: s.339). Oyuncu kendine bir yöntem belirleyerek hazırlanmalıdır. Ancak her durum için hazır yöntemler aramak oyuncuyu bazı kalıplaşmalara götürür. Bunun yerine kişisel sınırlamalar, engeller üzerine gidip, bunların üstesinden gelme yolları öğrenilmelidir. Bu doğaçlama yönteminde oyuncunun uç noktaya yönelen bir gerilimle, eksiksiz bir soyunuşla, kendi mahremiyetini çırılçıplak sergilemesiyle dışa vurulan "olgunlaşması" üzerine yoğunlaşmıştır. Oyuncu, kendine "nasıl yaparım?" sorusunu değil, "neyi yapmam?" sorusunu sormalıdır. Tüm çalışmalar oyuncunun kendi olanaklarını keşfi içindir, oyuncu iyi bir araştırmacı olmalıdır (Mimesis, 1992: s.66).

Grotowski’ nin oyuncunun sahnede dekor, kostüm, makyaj gibi etmenlerden yardım almadan, sadece bedeni ve sesi ile kendini ifade etmesi için geliştirdiği Yoksul Tiyatro yönteminde oyuncunun kişisel gelişimi ön plandadır.

Grotowski-Thomas Richards: Grotowski kendi faaliyetlerinin sonu, çalışmalarının varış noktası olarak saydığı Araç Olarak Sanat çalışmalarının temellerini, 1986 yılında Amerika'da, California 
Üniversitesi'nde atmıştır. Sanatçının ölümünden sonra bu çalışmalar Thomas Richards ve ekibi tarafından geliştirilerek devam ettirilmektedir.

Oyuncu eğitimi için farklı bir açı sunan Araç Olarak Sanat uygulamaları bedene meydan okuyan, sınırları aşmaya yönelen doğaçlama temrinleri yanında, geleneksel şarkılarla bedenin itkilerini harekete geçirme ve özgürleştirme yöntemi ile etki-tepki açısından önemli bir kaynak içermektedir. Eğitim aşamasında geleneksel şarkıların kullanılması Araç Olarak Sanat' a özgü bir yaklaşımdır. Şarkılarla beden aktif hale getirilir. Çünkü şarkı her zaman bedendir, bedende dolaşan yaşamın itkilerinden ayrılmaz. Bedende oluşan itkiler şarkının taşıyıcısı olurlar. Oyuncunun kendini, geçmiş geleneklerini, sesini ve duygularını tanımasını sağlar. Ayrıca diğer insanlarla empati kurması ve etki-tepki ilişkisini geliştirmesini getirecektir. Bu yöntemle uygarlığın getirdiği yabancılaşma, insansızlaşma yerini doğal duyguların ortaya konmasına bırakabilir. Oyuncuyu özgürleştirerek, başkalarının duyguları ile karşılaşmasına olanak hazırlayarak, insani olanın öne çıkmasında son derece etkili olabilecek yöntemlerden biridir (Richards, 1997: s.15).

Bu yöntem bireysel gelişimde dramatik sanatların araç olarak kullanılmasıdır. Gösterim öncesi hazırlık aşamasının önemi ve oyuncu için katkıları düşüncesi üzerinde yoğunlaşır. Provalar oyuncular için kendilerini keşfetme, yapabileceklerinin sınırlarını fark etme ve bu sınırlarını aşmaları için bir yaratı alanıdır [4]. Grotowski bu yönteminde, Stanislavski’ nin yaşamının sonlarına doğru geliştirdiği yönteme benzer bir yaklaşımda ilerlemiştir ama amacı rolü çözümlemekten çok, oyuncunun bu çalışma sırasındaki kendi gelişimine odaklanmıştır. Doğrudan dramatik karakterle uğraşmak yerine oyuncunun rolle bağlantılı olarak getireceği kişisel yaşantılar üstüne çalışmıştır. $\mathrm{Bu}$ yaşantılar sonradan rolle ilişkilendirilip, montajlanmıştır (Çevik, 2003: s.9).

Eugenio Barba: Bir süre Grotowski' nin yanında çalıştıktan sonra Danimarka' ya giderek, kendi çalışma yöntemini geliştiren Barba, dünyanın birç̧ok ülkesindeki oyunculuk yöntemlerini araştırarak, oyuncunun malzemesini en zengin kullanımı üzerine çalışmalara yönelmiştir. Barba, tiyatroda disipline ve eğitime verdiği önemin yanı sıra, benimsediği bazı oyunculuk ilkeleri açısından da Stanislavski ile benzerlikler taşır. Benzerlik taşıyan oyunculuk ilkeleri; anlatım yerine coşkusallığa yönelik oynama ve gündelik yaşama has özelliklerden sıyrılmadır. Ancak Stanislavski' den farklı olarak özdeşleşmeye karşıdır:

“Bir rolü oynamak karakterle özdeşleşmek anlamına gelmez. Oyuncu rolünü ne yaşar ne de dışarıdan resmeder. Karakteri kendi doğasıyla boğuşma, kişiliğinin gizli katmanlarına ulaşma, en acı veren ve sir dolu kalbinin en derininde yatan şeylerden slyrlma aracı olarak kullanir."(Barba, 1995: s.49-50) 
Barba oluşturduğu Tiyatro Antropolojisi Okulu ile düzenli olarak dünyanın farklı ülkelerinden sanatçıların bir araya geldiği atölyeler yaparak, oyuncunun söze dayalı oynaması yerine, dünyanın neresinde oynarsa oynasın, anlaşılması üzerine doğaçlama temrinleri geliştirmektedir. Oyuncunun bedeni ve bilincini yöneten ve seyircinin ilgisini üzerine çekmesini sağlayan ilkeleri bulup, saptamak amacındadır. Oyuncunun ağırlık merkezlerini değiştirerek, beden dengesinin bozulması, harekette karşıtlıkların dikkate alınması ve enerji kullanımı üzerine çalışmalar yapar (Barba, 1995: s.9). Oyuncunun genellikle sesi ve yüzü ile oynayıp, bedenini yeterince ifadeli kullanmadığına dikkat çekerek, bedenin kullanımı geliştirme yolunda temrinler üretmektedir.

Peter Brook: Grotowski gibi oyuncuda insanı araştırarak, insanın gerçek benliğine kavuşmasının yollarını arayan Brook, sahne ile yaşamı birleştiren denemeler yapar, boş bir mekanda yaratıcılığı kışkırtmaya yönelir. Hızla değişen yaşamda, kullanılan yöntemin daima değişmesi gerekliliğini öngörür. Stanislavski' nin günümüz tiyatrosunda belirleyici olabileceğinden kuşku duyar. Aktör Stüdyosu' nun kullandığı temrinleri çok abartılı bulan Brook, bu yöntemin geliştiği dönemlerde gereksinimlere yanıt verebildiğini, ancak günümüzde yaşamın doğalcı betimlemesinin artık kendilerini yönlendiren güçleri anlatmaya yetmediğini vurgular;

“Oyunculuk sanatına bilim ve bilgi açısından yaklaşan Stanislavski’ nin büyük dizgesi, bu dizgeyi yeterince yanlış okuyan ve içinden yalnızca adiden nefret etmeyi çıkaran genç oyunculara iyilik ettiği kadar kötülük de etti." (Brook, 1990: s.151).

Brook, oyuncunun yaratıcılığını ortaya çıkarmak için uğraşır. Biçemin ve özgürlüğün, disiplinin ve spontanlığın diyalektiğini araştırmak tiyatrodaki çalışmalarının temelini oluşturur (Bradby, Williams, 1988: 149). Oyuncularından her zaman hiçbir şey bilmiyormuş gibi sıfır noktasından başlamalarını ister. Çünkü dünün doğruları bugün anlamsızlaşır. Her yeni şey, yeni bir başlangıç gereksinir. Bu nedenle yapılan doğaçlamalar her yeni durum ve değişen tempoya uygun olacak biçimde gerçekleştirilmelidir. Böylece her an, o anı besleyen koşullara uygun biçemler doğabilir. Bu nedenle yaratıcı süreçte doğaçlamayla elde edilen biçemler kesinlikle gereklidir (Brook, 1988: s.202).

Viola Spolin: Chicago'da Neva Boyd tarafından yönetilen 'Yeniden Yaratım Eğitim Okulu' nda çalışmaya başlayan Spolin'in getirdiği en büyük yenilik, oyunları eğitimde ve özellikle oyuncu eğitiminde kullanmasıdır. Sanatçı oyun duygusuna çok önem vermiş, yaratıcılığın motor gücünün bu duygu olduğunu vurgulamıştır. Onun için, en önemli unsurlardan biri, oyuncuların kişisel olarak özgürleşmesidir: "Birbirine ve çevreye karşı açık olmak, dolaysız bir ilişki kurmak ve oynamaya isteklilik” önemlidir (Schmitt, 1990: s.15). 
Görüşlerinin oluşmasında Stanislavski'nin de etkisi olduğunu belirtmesine rağmen Spolin, Stanislavski' nin 'oyunculuk inanmaktır' ilkesine karşı çıkmıştır. Spolin, oyuncunun içinde bulunduğu anda var olmasını, eylemlerinin varsayılan bir yerde değil, sahnede gerçekleştiğini unutmamasını önerir ve sahnede boş anların olmaması gerektiğini vurgular (Spolin, 1986: xi).

Uyum temrinleri üreten Spolin 'anlamsız kelimeler' gibi doğaçlama temrinleri geliştirerek, oyuncunun sadece sözlü iletişimi kullanması yerine bedenini ve mimiğini de aktif kullanımını geliştirmeye yönelik çalışmalar yapmıştır. 'Kim, nerede, ne zaman, nasıl, niçin' gibi oyunculuğun temeli olan çalışmaları, kazandırdığı yeni doğaçlama temrinleriyle zenginleştirmiştir.

Joseph Chaikin: Yalnızca tiyatronun sahip olduğu özel güçleri araştıran Chaikin, Grotowski gibi oyuncuya yönelerek, oyuncunun kendi olmasını, kendini bulmasını ve yaşamla sanatı birleştirmesini hedefler. Çalışmalarında değişimin gerekliliğini, deneyselliği ve bir parça da risk almanın önemini vurgulayan sanatçı, takım ruhu içinde yaratının esas olduğuna inanır.

Oyuncunun iç disipline sahip olması gerektiği düşüncesinden hareketle, oyuncu yetiştirmede ilk adımın oyuncunun kendi içinde temiz bir alan bulunmasını sağlamak olduğunu belirtmiştir. Ona göre, geleneksel eğitim yöntemlerinde, oyuncular birçok gereksiz duygusal deneyimlerle doldurulmaya çalışılır. Oysa bunun yerine, oyuncunun nereden soluk almaya başlayacağı bulunmalıdır. Oyuncu, öncelikle kendi bedeninin ve sesinin olanaklarını kullanmalıdır. Başkalarını taklit etmemelidir. Ses ve duyular karşılaşılan her şeye karşı ve içinde bulunulan her ortamda kendini var edebilmelidir. İkinci olarak, beden tümüyle uyanık hale getirilmelidir. Ani durumlara reaksiyon vermede, imgeleri kullanmada hep duyarlı olmalıdır. Çağdaş tiyatronun gereksindiği, kilitli olmayan beden ve sese sahip bir oyuncudur (Chaikin, 1995: s.66-67).

Chaikin'a göre, oyuncu kendini açmalı, kendisi için varolabilmeli, keşfetmeli, kendini aramalı ve kendine açık olup, gelişimini yönlendirebilmelidir. Denemekle her şeye ulaşılabilir Bu düşüncelerden hareketle yaşamla sanatı birleştiren, takım ruhuna dayalı geliştirdiği 'içsel-dışsal', 'odaklaşma', 'yaşamdan masklar', 'transformasyon' gibi doğaçlama temrinleri ile oyuncu eğitimi için bir çok verimli temrinler üretmiştir.

Augusto Boal: Brezilya'da Arena Tiyatrosu' nda oyuncu laboratuvarı kuran Boal, sadece oyuncunun değil, isteyen herkesin oynayabileceği düşüncesinden hareketle, seyirciyi, oyuncuya/katılımcıya dönüştürmeye yönelik doğaçlama temrinleri kullanmaktadır.

Ağırlıklı olarak Stanislavski’ nin geliştirdiği doğaçlama temrinlerini kullanan Boal bu temrinlerle, duyguların ortaya çıkarılmasını amaçlamaktadır. İnsanların bedenlerinde barındırdığı belli alışkanlıklar 
nedeniyle, belirli tepkiler verilmesinin önüne geçilmesi gerekliliğine inanarak, oyuncunun bedeninin nasıl mekanikleştiğini araştırmaya girişmiştir.

Toplu paylaşım, üretim ve tartışmaya dayalı bir anlayışla yaklaşan Boal' in amacı oyuncuyu yaptığı her şeyi tüm benliği ile yapmaya yöneltmek ve alışkanlıklardan sıyrılıp, gerçekten görmesini, duymasını ve dokunmasını sağlayarak tüm duyularını açık hale getirmektir: Dokunma ve hissetme arasında köprü kurmak, duyma ve dinleme, bir anda çeşitli algılar geliştirme, bakılanı görme ve son olarak ise duyuları uyandırmak için anıları kullanma yolunu seçer (Boal, 2003: 43).

Boal, harekete dayalı bir anlatımı ön plana alarak oluşturduğu 'İmge Tiyatrosu' gibi yöntemlerle oyuncunun her zaman, her yerde rahatlıkla anlaşılmasına yönelik doğaçlama temrinleri geliştirerek, oyuncu eğitim yöntemine yenilikler katmaktadır.

Keith Johnstone: 1950' lerde İngiltere' de ilk doğaçlama tiyatrosunu kurup, yaşama geçirerek tiyatroda yerini alan sanatçı, doğaçlamanın bireysel eğitimde olduğu kadar, takım çalışmasının gelişiminde de değerini göstermiştir. Johnstone' un amacı, doğaçlamalar yoluyla, çocukların ve yetişkinlerin kendilerinde var olan yaratıcı imgelem güçlerini keşfetmelerini sağlayarak, bu yetilerini kullanabilmeleri için zemin hazırlamaktır (Johnstone, 1972: s.10).

Spontanlık ve beden dilinin zengin kullanımı üzerine yoğunlaşan Johnstone, doğaçlamayı kendi geliştirdiği yöntemle gerçek dışı öykülerden yola çıkarak, sözel veya özgür yaratıya dayalı sezgisel duyarlılıkla ve maske çalışmaları üzerine geliştirdiği temrinlerle sürdürür. Stanislavski ve Vakhtangov'un geliştirdiği maske çalışmalarını kullanan sanatçı, maske ile yapılan çalışmalarda oyuncunun kendini daha iyi tanıdığı, sınırları ile yüzleşebilme şansı elde ettiğini görerek, bu alanda doğaçlamalar üretmeye yönelmiştir. Oyunculuk eğitimine en büyük katkısı 'statü', 'maskeler', 'anlatı yetisi' gibi temrinler üreterek oyunculuğa yeni bir bakış getirmesi olmuştur.

Johnstone' un 1972 yılında yayımladığı Doğaç, Doğaçlama ve Tiyatro kitabında, sadece doğaçlamaların nasıl yapılacağı üzerinde durduğu görülür. Çünkü doğaçlamaların başarıya ulaşmasının eğitmene bağlı olduğuna inanır. Ona göre aynı doğaçlama yöntemini kullanan iki eğitmenin aynı sonuçlara ulaşması beklenemez. Ancak eğitmen yetenekli ise iyi sonuçlar ortaya çıkabilir düşüncesindedir.

\section{Sonuç}

Geçmişi çok eskilere dayanan doğaçlama, günümüzde oyuncu eğitiminde önemli bir yöntem olarak yerini korumaktadır. Doğaçlama yöntemi ile oyuncunun kendini, bugününü, geçmiş geleneklerini, bedenini, sesini ve duygularını tanımasını sağlamak, diğer insanlarla empati kurması ve etki-tepki 
ilişkisini geliştirmesinin önünü açmak hedeflenmektedir. Bu yöntem ile, uygarlığın getirdiği yabancılaşma, insansızlaşma yerine, doğal duyguların ortaya konmasına çalışılmaktadır.

Doğaçlama, oyuncunun tıpkı çocukluğunda olduğu gibi yeniden oynayabilmesi, oyun oynamanın yaşamdaki birçok duygunun ifadesine olanak tanıdığını hissedebilmesi, yaratabilmesi, yaratıcı olabilme becerisi kazanması, toplumun öngördügü, belirlenmiş, donuk bir yaşamı tekdüze sürdürmek yerine, yeni alternatiflerle yaşamını renklendirebilmesi, çeşitlendirebilmesi ve dolayısıyla da yaşamını zenginleştirebilmesi olasıllı̆ı sunma gibi yararlar sağlar.

Doğaçlamalar özellikle oyuncular için kendilerini keşfetme, yapabileceklerinin sınırlarını fark etme ve bu sınırlarını aşmaları için bir yaratı alanıdır. Doğaçlama yöntemi kullanımındaki amaç, oyuncuların bu süreci bir keşifler alanı olarak deneyimlemesine olanak tanımaktır. Doğaçlama yapmada başarısız olmak diye bir şey yoktur, çünkü bu yöntem tekrar tekrar deneme cesareti verir. Doğaçlama oynayan hatalarından yola çıkarak yeni şeyler öğrenir ve başka oyuncuları da gözlemleyerek doğruları bulmaya çalışır. Bu çalışmalarda baskın bir lider yoktur. Herkes kendi öğrenir, yönetici-lider de oyunculardan biridir.

Geliştirdikleri farklı doğaçlama yöntemleri ile oyunculuğu zenginleştirmeye çalışan belli başlı tiyatro sanatçılarından olan Stanislavski, Meyerhold, Brecht, Strasberg, Chekhov, Morris, Grotowski, Richards, Barba, Brook, Spolin, Chaikin, Boal ve Johnstone' un ortak amaçları söyle sıralanabilir: Oyuncunun kendini tanıması ve böylece kendini dışa açabilmesi, kendi ile diğerleri arasındaki benzerlik ve farklılıkların ayırdına varması, çevresindeki insanlar ve nesnelerle ilişkilerini geliştirmek, bunların sonucunda yaratıcılığını arttırmak ve 1960' lardan bu yana iyice belirginleşmeye başlayan "insansızlaşma" nın önüne geçerek, insanlar arasındaki iletişim ve etkileşimin etkin kılınmasına katkıda bulunmaktır.

Stanislavski' nin çalışma disiplini, çalışmak için laboratuvar oluşturması ve oyuncu odaklı çalışmanın temellerini atması ile geliştirdiği doğaçlama temrinleri, tüm sanatçıların tiyatroya yaklaşımlarını etkilemiştir. Zaten tüm sanatçılar doğaçlama temrinleri üretirken birbirlerinin yöntemlerinden yola çıkarak, birbirlerinin yöntemine alternatif yöntemler ortaya koymakta ya da bilinen doğaçlamaları alıp, değiştirip, geliştirme yoluna gitmektedirler. Bütün bu arayışlara süreklilik kazandırmak içinde araştırmauygulama laboratuvarına gereksinim duymuşlardır. Böylece genç oyunculardan oluşan bir topluluk kurarak okul gibi çalışma yolunu izlemişlerdir. Onların liderliğindeki bu laboratuvarlarda oyunculuk sanat1, günlük çalışma temrinleri, doğaçlamalar ve her tür yeniliğe açık, özgür denemelerle araştırılmaktadır. Sonuç olarak, her birinin gerçekleştirdiği uzun soluklu uygulamalarla oyunculuk eğitimine yeni bir ivme kazandırdıkları söylenebilir. 
Doğaçlamaların orada o anda üretilmesi yaşam zenginliği kazandırır. Çağdaş tiyatronun yapısı gereği, 'o an' önemlidir. Bu doğaçlamaları yapanlar, yapma koşulları ve bulundukları mekanın özelliklerine göre doğaçlamalar farklılaşmaktadır. Bu çalışmalar her yinelenişlerinde yeniden üretilirler.

Ülkemizde oyunculuk eğitimi veren üniversite, çeşitli kurum ya da kurslarda oyunculuk temel eğitimi çoğunlukla sadece 1930'larda Stanislavski’nin geliştirdiği yönteme dayalı sürdürülmektedir. Üstelik yaygın olarak kullanılmakta olan bu yöntem, Stanislavski' nin yaşamının sonlarına doğru geliştirdiği yenilikleri de içermemektedir. Yönteminin aynen alınıp, uygulanmasından kaygı duyan Stanislavski' ye rağmen, hızla değişen, gelişen yaşam koşullarında sadece bir doğaçlama yöntemini tek doğru gibi alıp kullanmak, oyuncu eğitimi için büyük bir hata olacaktır. Gelişen yaşam koşullarına göre oyunculuk eğitimi de kendini yenilemeyi sürdürmelidir.

Oyuncu eğitimine yeni ufuklar getirebilecek farklı doğaçlama yöntemlerinin katılımcıların özelliklerine, çalışma koşullarına ve çalışmanın amaçlarına göre uygulamalarla denenmesi ve geliştirilmesi yerinde olacaktır. Çağdaş oyunculuk eğitimi için, gelişmekte olan yaşama ve insana uyumlu, geçmişten günümüze yapılmış ve yapılmakta olan tüm oyunculuk araştırmalarını ve uygulamalarını izlemek ve ulaşılan sonuçları, belirlenecek amaçlar doğrultusunda deneyerek, geliştirmek ve doğaçlamalarla yeniden üretmek gereklidir.

\section{Kaynaklar}

Barba, E. (1995). The Paper Canoe, London: Routledge.

Boal, A. (2003). Oyuncular ve Oyuncu Olmayanlar için Oyunlar, (Çev. B. Ataman, Ö. Öztürk, K. Rızvanoğlu), İstanbul: B.Ü.Y.

Bradby, D. ve Williams. D. (1988). Directors' Theatre, London: Macmillan.

Brecht, B. (1981). Epik Tiyatro (Çev. Kamuran Şipal), İstanbul: Say Yay.

Brook, P. (1988). A Theatrical Casebook (Compiled David Williams), London: Methuen.

Brook, P. (1990). The Shifting Point, London: Methuen.

Chaikin, J. (1995). The Presence of the Actor, Theatre Communications Group, New York: Second Printing.

Çalışlar, A. (1993), 20. Yüzyılda Tiyatro, İstanbul: Mitos-Boyut Yay.

Çevik, K. (2003). Derinlikli fiziksel devinimin önemi ve birbirinin devamı ikiUsta: K.S. Stanislawski, J. Grotowski, Tiyatro Araştırmaları Dergisi, 15, Ankara: AÜ, TAD.

Ebert, G. (1999). Oyunculuk Sanatında Doğaçlama, İstanbul: Mitos-Boyut Yay. 
Ergün, S. (1993). Çă̆daş Doğaçlama, İzmir: Dokuz Eylül Yay.

Hançerlioğlu, O. (1995). Düşünce Tarihi, İstanbul: Remzi Kitabevi.

Johnstone, K. (1972). Impro Improvisation and the Theatre, New York: Routledge.

Mimesis, (1997). 6, İstanbul: Boğaziçi Üniversitesi Yay.

Morris, E. ve Hotckis. J. (2000). Rol Yapmayın Lütfen (Çev. İpek Bilgin), Ankara: Dost Kitabevi.

Morris, E. (2002). Futursuz Oyunculuk (Çev. İpek Bilgin), Ankara: Dost Kitabevi.

Nutku, Ö. (1998). Gösterim Terimleri Sözlüğ̈̈, İstanbul: İnk1lâp Kitabevi.

Picon-Vallin, B. (1997). Tiyatro-Devrim ve Meyerhold (Çev. Ali Berktay) İstanbul: Mitos-Boyut Yay.

Richards, T. (1997). The edge-point of performance, Documentation Series of the Workcenter of Jerzy Grotowski, Pontedera.

Schmitt, N. C. (1990). Actors and Onlookers, Theater and Twentieth-Century Scientific Views of Nature, USA: Northwestern University Press Evanston.

Spolin, V. (1986). Theater Games for the Classroom A Teacher's Handbook, U.S.A: Nortwestern University Pres.

Stanislavski, K. (1993). Bir Aktör Hazırlanıyor (Çev. Suat Taşer), İzmir: İleri Kitabevi.

Şener, S. (1991). Dünden Bugüne Tiyatro Düşüncesi, Eskişehir: T.C A.Ü Devlet Konservatuvar1 Yay.

[1] http://www.iusozluk.net/vsevolod+meyerhold.iu

[2] http://www.tiyatrotarihi.com/tiyatro_terimleri/biyomekanik_yontem_nedir.html

[3] http://www.chevhovactors training.com/chekhov.asp

[4] http:/www.chekhov.net. 


\title{
Summary
}

\section{Different Improvisatıon Techniques On Acting Education}

\author{
Selda ERGÜN.
}

\author{
Dokuz Eylül University
}

\begin{abstract}
Introduction
Evolution of systematic methods in theater acting education got speed by 20. century. In this period, exploring human in actor is aimed with actor pivotal studies. Thus, actor will be informed about himself by his education and changed himself, and also set possibility of changing of audience who integrate theater life and share this life.
\end{abstract}

\section{Concept of Improvisation}

Improvisation that qualified differently according to usage aim; is especially applied for actor to recognize and discover his own possibilities, meet face to face with his limits and ensure to expand his limits.

It is assisted for person to know himself in multiaspect with the studies of observation, improving perception, enrichment of simulacrum, mutual interaction and studies based on rhythm. All these studies provide actor to smooth away from monotonity and commonness, and to be inspired against to instantaneous situations, and also help actor to identify especially his mentality, his body and his acoustic and to use them overall capacity. Improvisation strengthens indirect and spontaneously relations that person who knows himself, has familiarized around his world.

\section{History of Improvisation}

It is run across with the first examples of improvisation theater in Mimus and Pantomimus in archaic age. In the course of time, plays which are written by improvisation has started to succeed Mimus' position. At the end of 15 . century, in the beginning of 16 . century a return to actor pivotal theater was experienced with Commedia dell' Arte which was a Italian folk improvisation theater. As from 1960's, actor pivotal theater understanding of modern artists has became widespreaded. 


\section{Improver Artists of Improvisation Methods}

Kontanstin Stanislavski: Stanislavski who developed his method in the 20. century, can be ranked as pioneer of modern usage of improvisation. With the realistic acting method which he developed in 1930's, he opened up the way of imroving actor's all mental, physical and enthusiastic power and presenting them to the audience. He used improvisation as a method in creating characters. The artist always worried about appropriation of his studies as hard rules and he assimilated the idea of that his method set the light to other artists and accelerate new leaps.

Vsevolod Emilyeviç Meyerhold: Meyerhold, intensified over improving a style which is peculiar to scenic and with the theater rhythm in actor's study, with the behaviour of actor's being a sculpture who is three dimensional, active and moving in the scene. He expected liveliness from the theater and provided actor to use all motion possibilities with his biomechanic technique.

Bertolt Brecht: Brecth who made real revolutions in 20. century's theater, improved the techniques of social gesture and alienation technique for acting. His aim was showing social reals by concrete and living tableaus in the scene, making audience think of and attracting them to judge. Hence, he used the alienation technique between scene and audience, scene and actor, and, actor and his role.

Lee Strasberg: He used Method Acting technique but different from Stanislavski, he thought necessary that focusing theraphy studies in the cause of holding role's orginal feeling by actor. Strasberg designed the Method as a means of offering the actor the opportunity to pursue their craft systematically, to gain an in depth knowledge of their own unique artistic voice, and to master the tools that allow an actor to powerfully express their truth.

Mikhael Chekhov: He researched on if creativeness is coincidencal or is related with education. According to Chekhov, in acting education, improvisation trainings such as increasing concentration must follow the training of person's recognizing himself and training of realizing limits. Education must supported with trainings about providing balance between thinking, feeling and wishing that are aimed at maintaining mental and physical harmony.

Eric Morris: He worked out improvisations studies based on Method Acting technique upon improving actor's recognizing himself and developing expression ways of actor. He allows the actor to bring to each role the uniqueness of his or her own individual personality and talent and in dealing with the actor's instrument in the belief that it is virtually impossible for an actor to learn or execute a process of acting without first eliminating the blocks, tension, fears, inhibitions $\mathrm{He}$ tended absolutely workmanship process with his last study 'Irreverent Acting'. 
Jerzy Grotowski: Grotowski who enforced most systematical labratory study after Stanislavski, put forward that actor's sound and body control and discipline of studying. Grotowski believes that acting education is necessary for person's finding the real about himself and getting out of masks which people hide behind every day. Improvisation trainings are important for actor's expression of himself only with his sound and body and without taking help of factors such as decor, costume and make up in the scene.

Grotowski-Thomas Richards: Applications of Art as a Tool includes very important resource for reflection-rebound with the technique of activating body's impulses and becoming free with traditional songs and also for trainings of challenging to body and going beyond the limits.

Eugenio Barba: Barba has developing improvisation trainings about being understood of actor wherever plays the game in the world rather than acting stick to words. Generally he plays with actor's sound and face and by the way he points to actor not to using body expressive enough and generates trainigs for improving body usage.

Peter Brook: Brook who does experimentations about combining art and life, tends to instigate creativity in empty places in stead of using factors that remove theater form its genuine. He anticipates that living method must change continuously in the quickly changing life.

Viola Spolin: The biggest innovation brought out by Spolin is using play in education, especially actor education. According to her, one of the most important factor is actor's individually becoming free. Scene is not a magic place that isolated from life.

Joseph Chaikin: Chaikin who researched only the special power of theater, believed that actor must have internal discipline and wanted to provide actor to recognize body's and sound's possibilities and he created improvisations towards to get body completely conscious.

Augusto Boal: Boal generally used trainings that are improved by Stanislavski. Boal has aimed at bringing into light the feelings with these trainings. Otherwise, he developes trainings about collective sharing, production and discussion and integrates innovations to actor education method.

Keith Johnstone: Johnstone who focused on affluent usage of body language and being spontaneous, used mask studies developed by Stanislavski and Vakhtangov. He observed that actors recognize themselves better and have a chance to meet face to face with their limits and Johnstone tended to generate improvisations in this susceptive.

\section{Conclusion}

Improvisation method history of which came from very early times, today protects its place as an important tool in acting education. Collective aim of main artists who have developed different 
improvisation methods in order to enrich acting, can be counted in this wise; actor's recognizing himself and thus open up himself outside, improving relations with people and objects, hence increasing creativeness and contributing to creating better human after getting away from "unmannedness" that has crystallizing till 1960’s.

In our country, universities, various institutions or training classes that give acting education, fundamental acting education is usually continued only based on Stanislavski's method that he improved in 1930's. Also, this common method does not include innovations that Stanislavski improved in the last times of his life.

For modern education, following all acting researchs and applications that is done or continued to doing from past to today which are harmonic with progressing human and life, besides, results must be developed directed to determined goals by experiments. It is more favorable that these approachs which can be get new innovations to acting education, should be tried and be improved according to study's aims, working conditions, chasractheristics of participants. 
